\title{
Eye and Rheumatology
}

\author{
Abdullah A Al-ghamdi
}

\subsection{Introduction}

The ocular involvement in rheumatology can be in a wide variety; it ranges from simple episcleritis to significant visual loss. Early detection followed by appropriate management can reserve vision. Ophthalmic involvement may occur in all of the rheumatic disorders. Ocular manifestation may be a presenting sign in some disorders, as in juvenile idiopathic arthritis (JIA), ankylosing spondylitis (AS), and Sjogren's syndrome ( $\mathrm{SjS})$, or can be a presenting sign with the systemic involvement as in systemic lupus erythematosus (SLE), polyarteritis nodosa (PAN), granulomatosis with polyangiitis (GPA), and systemic sclerosis. Thus ocular manifestations in rheumatologic diseases (Table 19.1) can be the link in approaching the diagnosis.

Detection of the ocular manifestations can be simple, yet the cooperation with ophthalmologists is crucial in some conditions. The major manifestations of ocular involvement in rheumatic disease include uveitis, scleritis, retinal vascular disease, neuro-ophthalmic lesions, orbital disease, keratitis, and $\mathrm{SjS} .\left(^{*}\right)$.

Approximately $16 \%$ of patients with RA have ophthalmic manifestations including scleritis and peripheral ulcerative keratitis PUK, a condition characterized by inflammation and thinning of the peripheral cornea, which may lead to perforation and blindness. While in patients with Adamantiades-Behçet's disease (ABD) ocular involvement occurs in approximately $70 \%$, and characterized by recurrent, explosive exacerbations of intraocular inflammation most commonly presenting as a posterior uveitis or panuveitis accompanied by a destructive retinal vasculitis, ocular or orbital involvement of Wegener's granulomatosis is seen in approximately $29-52 \%$ of the patients with PUK, corneal granuloma, episcleritis, necrotizing scleritis, or uveitis [1].

Concerning the ocular manifestations of rheumatic conditions, another aspect to shed light on is the side effects of medications used in the treatment of rheumatic diseases, for instance, one of the most serious side effects of hydroxychloroquine is toxicity in the eye.

In this chapter ocular manifestations of rheumatic diseases will be discussed along with historical points, basic ophthalmological examination, investigation, and management.

\subsubsection{Objectives}

By the end of this chapter, the reader is expected to construct an approach to the most common ocular presentations of rheumatic diseases, which 
Table 19.1 Ocular involvement in rheumatic diseases

\begin{tabular}{|c|c|}
\hline Rheumatic disease & Ocular involvement \\
\hline Rheumatoid arthritis & $\begin{array}{l}\text { Keratoconjunctivitis sicca } \\
\text { Scleritis } \\
\text { Episcleritis } \\
\text { Ulcerative keratitis } \\
\text { Superior oblique tendon sheath } \\
\text { syndrome }\end{array}$ \\
\hline $\begin{array}{l}\text { Juvenile idiopathic } \\
\text { arthritis }\end{array}$ & Uveitis \\
\hline $\begin{array}{l}\text { Systemic lupus } \\
\text { erythematosus }\end{array}$ & $\begin{array}{l}\text { Madarosis "loss of eyelashes" } \\
\text { Keratoconjunctivitis sicca } \\
\text { Scleritis } \\
\text { Ulcerative keratitis } \\
\text { Retinal vasculitis } \\
\text { Optic neuropathy }\end{array}$ \\
\hline $\begin{array}{l}\text { Granulomatosis with } \\
\text { polyangiitis }\end{array}$ & $\begin{array}{l}\text { Scleritis } \\
\text { Ulcerative keratitis } \\
\text { Orbital inflammatory disease } \\
\text { Nasolacrimal obstruction } \\
\text { Dacryocystitis }\end{array}$ \\
\hline Polyarteritis nodosa & $\begin{array}{l}\text { Scleritis } \\
\text { Ulcerative keratitis } \\
\text { Orbital inflammatory disease } \\
\text { Occlusive retinal periarteritis }\end{array}$ \\
\hline $\begin{array}{l}\text { Relapsing } \\
\text { polychondritis }\end{array}$ & $\begin{array}{l}\text { Scleritis } \\
\text { Acute anterior uveitis }\end{array}$ \\
\hline Systemic sclerosis & $\begin{array}{l}\text { Eyelid tightening and } \\
\text { Telangiectasia } \\
\text { Keratoconjunctivitis sicca }\end{array}$ \\
\hline Sjogren syndrome & $\begin{array}{l}\text { Keratoconjunctivitis sicca } \\
\text { Adie pupil }\end{array}$ \\
\hline Giant cell arteritis & $\begin{array}{l}\text { Arteritic anterior ischemic } \\
\text { optic neuropathy is the most } \\
\text { common } \\
\text { TIA } \\
\text { Central retinal artery occlusion } \\
\text { Cilioretinal occlusion } \\
\text { Ocular ischemic syndrome } \\
\text { Diplopia }\end{array}$ \\
\hline Psoriatic arthritis & $\begin{array}{l}\text { Anterior uveitis } \\
\text { Conjunctivitis } \\
\text { Secondary Sjogren syndrome }\end{array}$ \\
\hline Reiter syndrome & $\begin{array}{l}\text { Conjunctivitis } \\
\text { Acute anterior uveitis } \\
\text { Keratitis } \\
\text { Episcleritis } \\
\text { Scleritis } \\
\text { Papillitis } \\
\text { Retinal vasculitis }\end{array}$ \\
\hline Dermatomyositis & $\begin{array}{l}\text { Eyelid heliotrope rash } \\
\text { Periorbital edema and } \\
\text { erythema } \\
\text { Keratoconjunctivitis sicca } \\
\text { Scleritis } \\
\text { Cotton wool spot }\end{array}$ \\
\hline $\begin{array}{l}\text { Ankylosing } \\
\text { spondylitis }\end{array}$ & Uveitisscleritis \\
\hline
\end{tabular}

include uveitis, eye dryness, corneal ulcer, scleritis, episcleritis, and ocular side effects of rheumatic medications.

\subsection{Uveitis}

Uveitis is the inflammation of the middle layer of the eye, which includes choroid posteriorly, ciliary body, and iris anteriorly. Uveitis is a common manifestation of rheumatic and immunemediated disorders. The most common systemic immune disorders causing uveitis are spondyloarthritis (SpA). Those with HLA-B27-positive disease are likely to have earlier onset with more severe manifestations [2].

\subsubsection{Approach to Uveitis}

\subsubsection{History}

The main symptoms of anterior uveitis are eye pain and redness. These symptoms must be distinguished from other causes. Asking about constitutional symptoms and making systemic review in history aid you to target a specific diagnosis. Table 19.2 demonstrates the differential diagnosis of uveitis in terms of rheumatic diseases.

Sudden mood of onset, unilateral affection, and resolution of symptoms within few months with recurrence to the other eye are features suggestive for $\mathrm{SpA}$ (such as AS), reactive arthritis $(\operatorname{ReA})$. Keep in mind that males are more common to be affected with SpA than females.

Insidious mood of onset, bilateral affection, and chronic duration are features suggestive for

Table 19.2 Differential diagnosis of acute uveitis in respect to systemic immune diseases

\begin{tabular}{l}
\hline Juvenile idiopathic arthritis \\
\hline Relapsing polychondritis \\
\hline Ankylosing spondylitis \\
\hline Reactive arthritis \\
\hline Psoriatic arthritis \\
\hline Systemic lupus erythematosus \\
\hline Sjogren syndrome \\
\hline Behçet's disease
\end{tabular}


psoriatic arthritis which is more common in females than males.

Bilateral affection with episodic attacks that do not resolve completely is a feature suggestive for Behçet's disease.

Insidious mood of onset, bilateral affection, and chronic duration in young children are features suggestive for JIA. Keep in mind that uveitis in JIA is commonly accompanied with other complications like band keratopathy (calcium deposition in corneal epithelium), posterior synechiae (which is iris adhesion to the lens), cataract, and glaucoma. Rule out other causes by asking about HIV infection and its risk factors and about the status of immune system to rule out CMV infection and tuberculosis.

\subsubsection{Eye Examination}

Presence of leukocytes in the anterior chamber by slit lamp examination is characteristic of anterior uveitis. A haze or flare may also be seen which represents protein accumulation in the anterior part of the eye. Direct visualization of active chorioretinal inflammation and the presence of leukocytes in the vitreous humor behind the eye lens can also be a sign for posterior uveitis. Inflammation in the anterior chamber, vitreous, and choroid or retina is termed panuveitis.

\subsubsection{Treatment}

In patients with systemic disease associated with uveitis, the treatment for the systemic disease may or may not be enough to control the uveitis [3]. Treatment for uveitis can be given systemically or delivered directly to the eyes.

The main use of local therapy is for the treatment of unilateral or asymmetric disease [3]. Topical glucocorticoids are for anterior uveitis. Periocular or intraocular injections of glucocorticoids (e.g., Kenacort injection) in posterior uveitis or panuveitis. A dilating drop such as scopolamine or cyclopentolate can relieve pain due to papillary muscle spasm.

Systemic treatment is generally reserved for resistant uveitis and in glaucoma patients, who cannot be treated with local injection. In addition, patients with bilateral disease are often treated with systemic therapy. A small percent- age of patients with uveitis may require immunosuppressive medications. Absolute indications for their use include Behçet's syndrome, VogtKoyanagi-Harada syndrome, sympathetic ophthalmia, and rheumatoid sclerouveitis, while relative indications include intermediate uveitis, retinal vasculitis with central vascular leakage, chronic severe iridocyclitis or panuveitis, JRArelated iridocyclitis, and children with intermediate uveitis [4]. Additionally, patients who require a daily dose of $10 \mathrm{mg}$ or more of prednisone to control their ocular inflammation may benefit from a glucocorticoid-sparing agent, such as an antimetabolite, as a safer long-term alternative [5]. Infliximab and adalimumab are antitumor necrosis factor-alpha (TNF-a) drugs. It can be very useful in patients refractory to conventional therapy. [6] Interferon-alpha appears capable of inducing disease remission in patients with Behçet's disease [3]. Rituximab, an anti-CD20 (i.e., anti-B-cell) monoclonal antibody has been reported to be effective in patients with refractory scleritis due to Wegener's disease [3].

\subsection{Eye Dryness}

Also known as keratoconjunctivitis sicca, it is a multifactorial disease of the tears and ocular surface that results in symptoms of discomfort, visual disturbance, and tear film instability with potential damage to the ocular surface, accompanied by increased osmolarity of the tear film and inflammation of the ocular surface [7, 8]. Dry eye is the most recognized ocular manifestations of SLE together with lupus retinopathy [1].

\subsubsection{Approach to Dry Eye}

\subsubsection{History}

A good history probably guides you to the possible underlying cause of the dry eye like medications, weather conditions, or systemic diseases. Symptoms of dry eye can be burning or foreign body sensation, eye irritation, redness or dryness, and/or blurred vision. 
Table 19.3 Differential diagnosis of dry eye in respect to systemic immune-mediated diseases

\begin{tabular}{l}
\hline Rheumatoid arthritis \\
\hline Psoriatic arthritis \\
\hline Sjogren syndrome \\
\hline Systemic sclerosis \\
\hline Systemic lupus erythematosus \\
\hline Dermatomyositis \\
\hline
\end{tabular}

Contact lenses use, previous eye surgeries, chemical insult, Parkinson's disease, and familial history might give a hint about the possible cause of the dry eye.

Ocular dryness associated with mouth dryness increases the susceptibility of $\mathrm{SjS}$, which can be a primary disorder or a secondary disorder of other systemic immune-mediated diseases. Table 19.3 shows the differential diagnosis of dry eye in terms of rheumatic diseases.

\subsubsection{Eye Examination}

Use the slit lamp to examine the lacrimal glands, the conjunctiva, and the eyelids to assess meibomian gland function. Examine ocular surface by fluorescein stain to look for corneal abrasions and assess corneal sensation.

Assessment of tear film is also an important step using tear break-up time, in which fluorescein stain is used to assess the stability of tear film or Schirmer's test, quantitative measurement of tear production by each eye.

\subsubsection{Treatment}

The treatment of dry eye deepened on the severity of the condition; it includes artificial tear substitutes, gels/ointments, topical cyclosporine and corticosteroids, systemic omega-3 fatty acids supplements, systemic cholinergic agonists, systemic anti-inflammatory agents, mucolytic agents, autologous serum tears, punctal plugs, and tarsorrhaphy [9].

\subsection{Corneal Ulcer}

Ulcers are primarily divided into infectious and noninfectious categories. Noninfectious ulcers include autoimmune, neurotrophic, toxic, and
Table 19.4 Differential diagnosis of ulcerative keratitis in respect to rheumatological diseases

\begin{tabular}{l}
\hline Rheumatoid arthritis \\
\hline Systemic lupus erythematosus \\
\hline Granulomatosis with polyangiitis \\
\hline Polyarteritis nodosa
\end{tabular}

allergic keratitis, as well as chemical burns and keratitis secondary to entropion, blepharitis, and a host of other conditions.

\subsubsection{Approach to Corneal Ulcer}

\subsubsection{History}

Some patients are asymptomatic, while others present with mild symptoms of conjunctival swelling, hyperemia, and ocular irritation. There is a history of a systemic immune disorder such as RA, SLE, and GPA. It's essential that the treating rheumatologist manages the underlying immune condition. Examples of these immune conditions are listed in Table 19.4.

Moderate to severe ulcers can progress rapidly to melting and perforation.

\subsubsection{Eye Examination}

The appearance of noninfectious ulcers is often quite different from infectious lesions. Most notably, the underlying cornea is relatively clear without diffuse haziness or white blood cells. Sterile infiltrates smaller than $1 \mathrm{~mm}$ can be seen, as well as gray-white circumlimbal lesions.

\subsubsection{Treatment}

Sterile infiltrates are usually self-limiting and resolve within a week or two. If an ulcer does develop but is less than $2 \mathrm{~mm}$, fairly round, and peripheral, without much stromal involvement or inflammation, it is most likely a sterile ulcer which is very responsive to topical steroids.

Although systemic immunomodulation is required, some topical measures, such as lubricating the surface, may be helpful. The clinician may also consider using topical cyclosporine to help heal the eye and immunosuppressant drops such as ascorbate to reduce the risk of stromal melting [10-14]. 


\subsection{Scleritis}

Around $50 \%$ of patients present with scleritis have underlying systemic diseases. GPA is the most common vasculitic disorder to manifest with scleritis.

\subsubsection{Approach to Scleritis}

\subsubsection{History}

Ask about pain; scleritis presents with severe piercing eye pain that may worsen at night and awaken patients from sleep with ipsilateral referral to head or face. Other symptoms include photophobia and redness. Severe eye and periorbital pain that is progressive and worsen in the early morning are features suggestive for necrotizing anterior scleritis. Severe pain and difficult to localize, diplopia, ocular pain upon eye movement, and reduced vision are features suggestive for posterior scleritis. In your history cover constitutional symptoms and systemic review to target rheumatic diseases and also previous ocular surgery are important. A list of rheumatic causes of scleritis is in Table 19.5.

\subsubsection{Eye Examination}

Signs of scleritis include tender globe, sclera, and episcleral edema. Slit lamp examination in advanced disease shows blood vessel closure with scleral thinning and a bluish discoloration. Diffuse ocular erythema and scleral edema with no nodules or necrosis are features suggestive for diffuse anterior scleritis. Areas of localized tender edema with deep episcleral vessel dilatation are features suggestive for nodular anterior scleritis. Keep in mind that the eye in anterior scleritis appears red while in isolated posterior scleritis the eye appears white but there are other important signs in posterior scleritis which are detected by fundoscopic examination like choroidal folds,

Table 19.5 Differential diagnosis of scleritis in respect to systemic immune-mediated disease

\begin{tabular}{l}
\hline Rheumatoid arthritis \\
\hline Relapsing polychondritis \\
\hline Systemic lupus erythematosus \\
\hline Reactive arthritis
\end{tabular}

annular choroidal detachment, retinal folds, exudative retinal detachment, retinal vasculitis, optic disc edema, and posterior uveitis. Posterior scleritis can also cause glaucoma.

\subsubsection{Treatment}

Pain relief should be the goal of treatment. It could be achieved by topical lubricants, topical glucocorticoids, and oral NSAIDs. Treat the underlying disease. Azathioprine has been shown to be effective in the management of scleritis secondary to relapsing polychondritis. In necrotizing scleritis, cyclophosphamide is considered the treatment of choice. Infliximab has been used effectively in scleritis secondary to JIA, ankylosing spondylitis, Wegener granulomatosis, sarcoidosis, and Crohn disease [15].

\subsection{Episcleritis}

\subsubsection{Approach to Episcleritis}

\subsubsection{History}

Ask in your history about the mood of onset, eye redness and whether it is diffused or localized, and eye irritation because episcleritis usually manifests as an acute onset, localized or diffused eye redness, and/or irritation. Bilateral eye involvement may suggest an immune-mediated disease. Examples of these immune-mediated episcleritis are listed in Table 19.6.

\subsubsection{Eye Examination}

Shows vasodilatation of superficial episcleral vessels and episcleral edema.

\subsubsection{Treatment}

Treat the underlying disease. Pain relief should be the goal of treatment. It could be achieved by

Table 19.6 Differential diagnosis of episcleritis in respect to systemic immune-mediated disease

\begin{tabular}{l}
\hline Rheumatoid arthritis \\
\hline Systemic lupus erythematosus \\
\hline Behçet's disease \\
\hline Reiter syndrome \\
\hline Inflammatory bowel disease
\end{tabular}


topical lubricants, topical NSAIDs [16], topical glucocorticoids, and oral NSAIDs.

\subsection{Cataract}

Cataract is defined as an opacity in the lens of the eye. In rheumatology practice, cataract results from the use of topical or systemic glucocorticoids for treatment of immune-mediated diseases. The lens of the eye is composed of layers like an onion. The outermost is the capsule, the layer inside the capsule which is the cortex, and the innermost layer which is the nucleus. A cataract may develop in any of these areas and is described based on its location in the lens shown in Fig. 19.1. Risk factors and symptoms can be reviewed in Tables 19.7 and 19.8.

\subsubsection{Approach to Cataract}

\subsubsection{History}

Ask about vision difficulties experienced by the patient that may limit their daily activities and other general health concerns affecting vision.

\subsubsection{Eye Examination}

It includes visual acuity measurement to determine to what extent a cataract may be limiting clear vision at distance and near, refraction to determine the need for changes in an eyeglass or contact lens prescription, as well as slit lamp examination to determine the extent and loca- tion of any cataracts. It would be better to evaluate the retina of the eye through a dilated pupil to exclude any retinal disease. It is also advisable to measure the intraocular pressure. Supplemental testing for color vision and glare sensitivity could be done.

\subsubsection{Treatment}

The treatment of cataracts is based on the level of visual impairment they cause. If a cataract affects vision only minimally, or not at all, no treatment may be needed. Patients may be advised to monitor for increased visual symptoms and follow a regular check-up schedule. In some cases, a change in eyeglass prescription may provide temporary improvement in visual acuity.

Table 19.7 Risk factors for cataract

\begin{tabular}{l}
\hline Old age \\
\hline Diabetes mellitus \\
\hline Drugs, e.g., steroids and chlorpromazine \\
\hline UV light radiation \\
\hline Smoking \\
\hline Alcohol \\
\hline Nutritional deficiency \\
\hline
\end{tabular}

Table 19.8 Signs and symptoms of cataract

Blurred or hazy vision

Reduced intensity of colors

Increased sensitivity to glare from lights, particularly when driving at night

Increased difficulty seeing at night

Change in the eye's refractive error
Fig. 19.1 Types of cataract

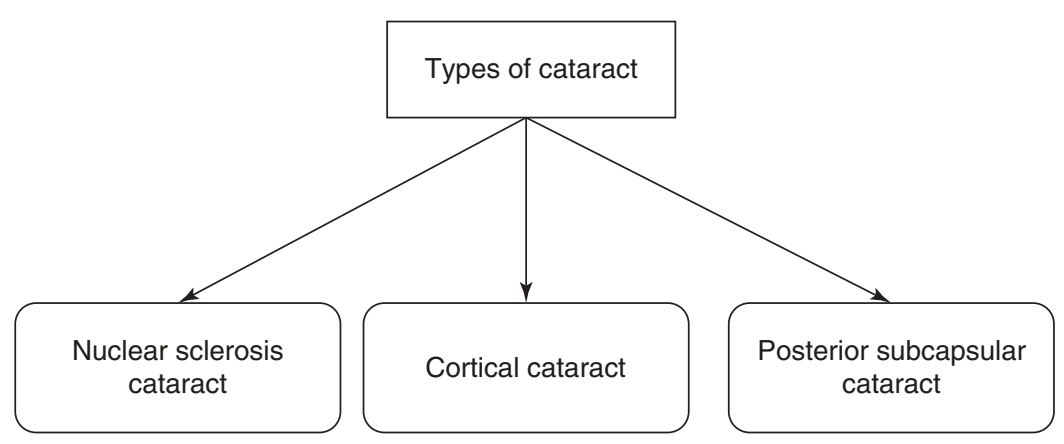


Fig. 19.2 Types of glaucoma

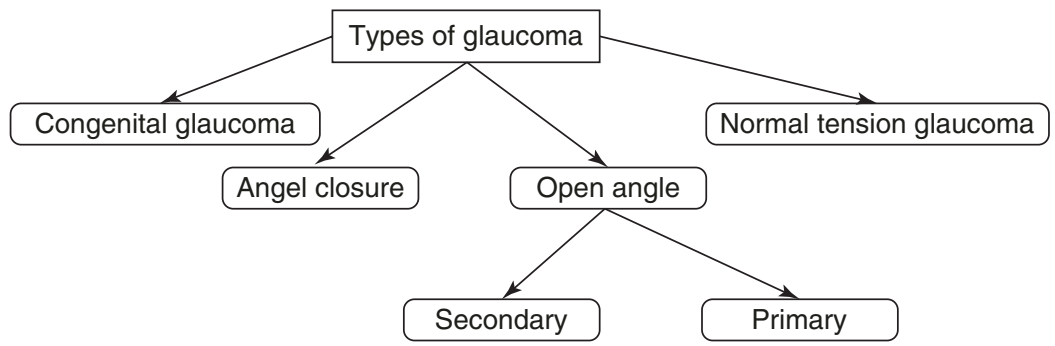

\subsection{Glaucoma}

Glaucoma is a group of eye disorders leading to progressive damage to the optic nerve. Like in cataract, glaucoma in rheumatology practice results from the use of topical or systemic glucocorticoids for treatment of immune-mediated diseases. It is usually associated with increased pressure inside the eye and is characterized by loss of optic nerve tissue resulting in loss of vision. Advanced glaucoma may even cause blindness. Figure 19.2 shows the types of glaucoma.

\subsubsection{Approach to Glaucoma}

\subsubsection{History}

Ask about any symptoms the patient is experiencing and the presence of any risk factors for glaucoma which are listed in Table 19.9.

\subsubsection{Eye Examination}

Measure visual acuity to determine the extent to which vision may be affected. Measurement of the pressure inside the eye is an essential step and can be done by tonometry or more preferably by applanation. Pachymetry to measure corneal thickness could be done for more accurate intraocular pressure estimation. Visual field testing, also called perimetry, is often done for glaucoma patients to check if the field of vision has been affected by glaucoma. Evaluation of the retina can be done to monitor any changes that might occur over time. Supplemental testing may
Table 19.9 Risk factors for glaucoma

\begin{tabular}{l|l}
\hline Age & $\begin{array}{l}\text { Increased risk after 60 years, after } \\
40 \text { years in people of African } \\
\text { descent }\end{array}$ \\
\hline Race & $\begin{array}{l}\text { Increased risk in African race (open } \\
\text { angle) and Asians (closed angle) }\end{array}$ \\
\hline Family history & $\begin{array}{l}\text { Increased risk in people who have } \\
\text { siblings or parents with glaucoma }\end{array}$ \\
\hline $\begin{array}{l}\text { Medical } \\
\text { conditions }\end{array}$ & Hypertension and heart diseases \\
\hline $\begin{array}{l}\text { Physical injury } \\
\text { to the eye }\end{array}$ & Like blunt trauma \\
\hline $\begin{array}{l}\text { Some eye } \\
\text { conditions }\end{array}$ & $\begin{array}{l}\text { Retinal detachment, eye tumors, } \\
\text { and eye inflammations, short axial } \\
\text { length, and hypermetropia }\end{array}$ \\
\hline Medications & Corticosteroid use \\
\hline
\end{tabular}

include gonioscopy, a procedure to give clearer views of the angle anatomy.

\subsubsection{Treatment}

The treatment of glaucoma is aimed at reducing intraocular pressure. The most common first-line treatment of glaucoma is usually prescription eye drops that must be taken regularly. In some cases, systemic medications, laser treatment, or other surgery may be required. While there is no cure as yet for glaucoma, early diagnosis and continuing treatment can preserve eyesight. Patients need to continue treatment for the rest of their lives. Because the disease can progress or change silently, compliance with eye medications and eye examinations are essential, as treatment may need to be adjusted periodically. Early detection, prompt treatment, and regular monitoring can help to control glaucoma and therefore reduce the chances of progression vision loss. 


\subsection{Ophthalmologic Side Effects of Rheumatic Medications [17]}

There are several ocular side effects of rheumatic medications (Table 19.10). It is well documented that corticosteroid use induces cataract and increases intraocular pressure causing glaucoma. Most common type of cataract induced by corti- costeroids is posterior subcapsular cataract. The incidence of posterior subcapsular cataract is associated with dosage of steroids use and duration of treatment. In a number of randomized, controlled trials, the incidence of corticosteroidinduced cataracts reported to be ranging from $6.4 \%$ to $38.7 \%$ after oral corticosteroid use [18, 19]. Glaucoma incidence has been reported in

Table 19.10 Ocular side effects of medications used in rheumatic diseases

\begin{tabular}{|c|c|}
\hline Steroids & $\begin{array}{l}\text { Cataract } \\
\text { Glaucoma }\end{array}$ \\
\hline Indomethacin & $\begin{array}{l}\text { Corneal opacity } \\
\text { Blurred vision } \\
\text { Retinopathy } \\
\text { Pigmentary changes of the macula }\end{array}$ \\
\hline Aspirin & $\begin{array}{l}\text { Subconjunctival hemorrhages and hemorrhagic retinopathies following } \\
\text { trauma (increases bleeding tendency) }\end{array}$ \\
\hline $\begin{array}{l}\text { Ibuprofen, naproxen, oxaprozin, and } \\
\text { piroxicam }\end{array}$ & $\begin{array}{l}\text { Increase bleeding tendencies } \\
\text { Blurred vision } \\
\text { Photophobia } \\
\text { Decreases central vision } \\
\text { Stevens-Johnson syndrome }\end{array}$ \\
\hline $\begin{array}{l}\text { Rofecoxib, celecoxib, valdecoxib, } \\
\text { lumiracoxib, nimesulide, and etodolac } \\
\text { which are NSAIDs selective for the } \\
\text { inhibition of cyclooxygenase (COX)-2 }\end{array}$ & $\begin{array}{l}\text { Conjunctivitis } \\
\text { Blurred vision }\end{array}$ \\
\hline Sulfasalazine & $\begin{array}{l}\text { Facial nerve palsy } \\
\text { Blurred near vision }\end{array}$ \\
\hline Abatacept & $\begin{array}{l}\text { Eye irritation } \\
\text { Allergic conjunctivitis } \\
\text { Blurry vision } \\
\text { Visual disturbance } \\
\text { Eye pruritus }\end{array}$ \\
\hline Rituximab & $\begin{array}{l}\text { Conjunctivitis } \\
\text { Transient ocular edema } \\
\text { A burning sensations } \\
\text { Loss of visual function }\end{array}$ \\
\hline Interferon alfa & $\begin{array}{l}\text { Retinal vascular abnormalities (retinal microvascular changes, presence } \\
\text { of cotton wool spots, intraretinal hemorrhages, retinal detachment) }\end{array}$ \\
\hline Methotrexate & $\begin{array}{l}\text { Periorbital edema } \\
\text { Ocular pain } \\
\text { Blurred vision } \\
\text { Photophobia } \\
\text { Conjunctivitis } \\
\text { Blepharitis } \\
\text { Decreased reflex tear secretion } \\
\text { Non-arteritic ischemic optic neuropathy }\end{array}$ \\
\hline Bisphosphonates & $\begin{array}{l}\text { Uveitis } \\
\text { Scleritis }\end{array}$ \\
\hline Chloroquine and hydroxychloroquine & $\begin{array}{l}\text { Keratopathy } \\
\text { Ciliary body dysfunction } \\
\text { Lens opacities } \\
\text { Outer retinal damage } \\
\text { Pigmentary retinopathy }\end{array}$ \\
\hline
\end{tabular}


patients using oral, intravenous, eye drops, intranasal, or inhalational steroids.

Indomethacin is one of the most potent NSAIDs that has been associated with cases of corneal opacities and blurred vision, especially when used long term. Reports on ocular side effects from the usage of sulfasalazine are relatively few, including peripheral facial nerve palsy and blurred near vision in association with sulphasalazine treatment. Aspirin, ibuprofen, naproxen, oxaprozin, and piroxicam increase bleeding tendency which manifests in subconjunctival hemorrhages and hemorrhagic retinopathies following trauma.

Biologics are a new class of drugs which have become recently a choice to treat immunemediated diseases. Abatacept is a biologic agent which causes eye irritation, allergic conjunctivitis, blurry vision, visual disturbance, and eye pruritus involving less than $1 \%$ of the drug users. Another biologic agent is rituximab. In a clinical study concerning the efficacy of rituximab in 222 patients with lymphoma, 9 of them reported ocular side effects, including conjunctivitis, transient ocular edema, a burning sensation, and a transient or permanent loss of visual function [20]. Interferon alfa is an antiviral which is used as immunomodulator and has shown effectiveness in treating rheumatic diseases. Side effects of interferon alfa include retinal vascular abnormalities (retinal microvascular changes, presence of cotton wool spots, intraretinal hemorrhages, retinal detachment). Mostly, the ocular changes are transient and asymptomatic [21].

Methotrexate is an antimetabolite which is used to treat several rheumatic diseases. Ocular side effects of methotrexate include periorbital edema, ocular pain, blurred vision, photophobia, conjunctivitis, blepharitis, decreased reflex tear secretion, and non-arteritic ischemic optic neuropathy. Bisphosphonates are used in patients with chronic inflammatory diseases or patients with osteoporosis. Their use has been reported to cause uveitis and scleritis.

Antimalarials such as chloroquine and hydroxychloroquine cause keratopathy, ciliary body dysfunction, lens opacities, outer retinal damage, and pigmentary retinopathy.

\subsection{Antimalarial-Related Retinopathy}

\subsubsection{Approach to Antimalarial- Related Retinopathy}

\subsubsection{History}

There are many factors that may contribute to hydroxychloroquine retinopathy. These factors include daily and cumulative dosage which is the most important, duration of treatment, renal or liver disease, patient's age, and prior retinal disease. The great majority of case reports of hydroxychloroquine toxicity occurred in individuals taking more than $6.5 \mathrm{mg} / \mathrm{kg} /$ day or chloroquine at $3 \mathrm{mg} / \mathrm{kg} / \mathrm{day}$, and most of the reports of hydroxychloroquine toxicity at lower doses occurred in individuals who took the drug for at least 5 years.

\subsubsection{Eye Examination}

Consists of a dilated posterior-segment examination, along with Amsler grid testing or automated perimetry. Baseline fundus photographs and fluorescein angiography (FA) are helpful in patients with preexisting macular pigmentary changes. The patients should repeat visual acuity testing every 6 months, screen the visual field, use the Amsler grid, and have a detailed funduscopy. Central threshold visual field testing is recommended for suspected optic neuropathy.

\subsubsection{Treatment}

The only treatment for antimalarial related retinopathy is stopping the offending medication with consultation of the rheumatologist who is taking care of the patient.

Acknowledgments The authors would like to thank Moustafa Magliyah, MD, Danya Alwafi, MD, and Rawan Hawsawi, MD, for their contributions to this chapter in the previous edition. The authors also would like to thank Dr. Waleed Hafiz for his assistance in the development of this chapter.

\section{References}

1. Stockigt JR, Topliss DJ, Hewett MJ. High-renin hypertension in necrotizing vasculitis. N Engl J Med. 1979;300:1218. 
2. Miller NR. Visual manifestations of temporal arteritis. Rheum Dis Clin N Am. 2001;27:781.

3. Brooks RC, McGee SR. Diagnostic dilemmas in polymyalgia rheumatica. Arch Intern Med. 1997;157:162.

4. Watts RA, Scott DG. Recent developments in the classification and assessment of vasculitis. Best Pract Res Clin Rheumatol. 2009;23:429.

5. Deng J, Ma-Krupa W, Gewirtz AT, et al. Toll-like receptors 4 and 5 induce distinct types of vasculitis. Circ Res. 2009; 104:488.

6. Hunder GG, Arend WP, Bloch DA, et al. The American College of Rheumatology 1990 criteria for the classification of vasculitis. Introduction. Arthritis Rheum. 1990;33:1065.

7. Kyle V, Hazleman BL. Treatment of polymyalgia rheumatica and giant cell arteritis. II. Relation between steroid dose and steroid associated side effects. Ann Rheum Dis. 1989;48:662.

8. Sato O, Cohn DL. Polyarteritis and microscopic polyangiitis. In: Klippel JH, Dieppe PA, editors. Rheumatology. St Louis: Mosby; 2003.

9. Ribi C, Cohen P, Pagnoux C, et al. Treatment of polyarteritis nodosa and microscopic polyangiitis without poor-prognosis factors: a prospective randomized study of one hundred twenty-four patients. Arthritis Rheum. 2010;62:1186.

10. Dabague J, Reyes PA. Takayasu arteritis in Mexico: a 38-year clinical perspective through literature review. Int J Cardiol. 1996;54(54 Suppl):S103.

11. Sharma BK, Jain S, Sagar S. Systemic manifestations of Takayasu arteritis: the expanding spectrum. Int J Cardiol. 1996;54(54 Suppl):S149.
12. Nasu T. Takayasu's truncoarteritis. Pulseless disease or aortitis syndrome. Acta Pathol Jpn. 1982;32(Suppl 1): 117 .

13. Seyahi E, Ugurlu S, Cumali R, et al. Atherosclerosis in Takayasu arteritis. Ann Rheum Dis. 2006;65:1202.

14. Noris M, Daina E, Gamba S, et al. Interleukin-6 and RANTES in Takayasu arteritis: a guide for therapeutic decisions? Circulation. 1999;100:55.

15. Guillevin L, Pagnoux C. When should immunosuppressants be prescribed to treat systemic vasculitides? Intern Med. 2003;42:313.

16. Yoneda S, Nukada T, Tada K, et al. Subclavian steal in Takayasu's arteritis. A hemodynamic study by means of ultrasonic Doppler flowmetry. Stroke. 1977;8:264.

17. Kerr GS. Takayasu's arteritis. Rheum Dis Clin N Am. 1995;21:1041.

18. Jennette JC, Falk RJ, Andrassy K, et al. Nomenclature of systemic vasculitides. Proposal of an international consensus conference. Arthritis Rheum. 1994;37:187.

19. de Lind van Wijngaarden RA, van Rijn L, Hagen EC, et al. Hypotheses on the etiology of antineutrophil cytoplasmic autoantibody associated vasculitis: the cause is hidden, but the result is known. Clin J Am Soc Nephrol. 2008;3:237.

20. Falk RJ, Hogan S, Carey TS, Jennette JC. Clinical course of anti-neutrophil cytoplasmic autoantibodyassociated glomerulonephritis and systemic vasculitis. The glomerular disease collaborative network. Ann Intern Med. 1990;113:656.

21. Beck L, Bomback AS, Choi MJ, et al. KDOQI US commentary on the 2012 KDIGO clinical practice guideline for glomerulonephritis. Am J Kidney Dis. 2013;62:403.

Open Access This chapter is licensed under the terms of the Creative Commons Attribution 4.0 International License (http://creativecommons.org/licenses/by/4.0/), which permits use, sharing, adaptation, distribution and reproduction in any medium or format, as long as you give appropriate credit to the original author(s) and the source, provide a link to the Creative Commons license and indicate if changes were made.

The images or other third party material in this chapter are included in the chapter's Creative Commons license, unless indicated otherwise in a credit line to the material. If material is not included in the chapter's Creative Commons license and your intended use is not permitted by statutory regulation or exceeds the permitted use, you will need to obtain permission directly from the copyright holder. 